Peer review: This article has been subject to a double-blind peer review process

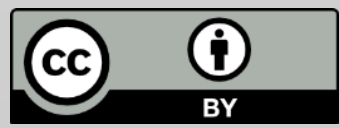

Copyright notice: This article is issued under the terms of the Creative Commons Attribution License, which permits use and redistribution of the work provided that the original author and source are credited.

You must give appropriate credit (author attribution), provide a link to the license, and indicate if changes were made. You may do so in any reasonable manner, but not in any way that suggests the licensor endorses you or your use. You may not apply legal terms or technological measures that legally restrict others from doing anything the license permits.

https://creativecommons .org/licenses/by/4.0/

\section{An Assessment of the Visual Appropriateness of Selected Brand Logos}

\section{Afeez Babatunde Siyanbola ${ }^{1}$, Adedola Olayinka Adeyemi}

Fine and Applied Art Department, Olabisi Onabanjo University, Ago Iwoye Nigeria

Correspondence: afeezsegun@yahoo.com ${ }^{1}$

\section{Abstract}

This paper focuses on assessing the appropriateness of selected logos of popular brands. The paper enunciates the relevance of logos to the public perception of brands. Logos function as signifiers, denotative, point of contact and identifiers. The visual components of logos and the suggestive meanings of shapes which are the building blocks of the pictorial contents are articulated in this study. Thirty (30) logos of popular brands were purposively selected and subjected to the analysis of Eighty (80) people constituting thirty (30) formally trained practicing graphic designers, ten (10) experienced printers and forty (40) individuals who are familiar with the selected brands. The collated data were analyzed using the Statistical Package of Social Science (SPSS). Findings revealed that logos are visual seals that communicate brand promises to the targeted audience, viewers recall simple logos more easily and logos crammed with colours are not appealing. The study recommended that visual contents of logos should resonate balance, application colours in logos should be limited to two and logos design should be a product of a sound brand strategy.

Keywords: logo; simplicity; memorability; versatility; distinctness; appropriateness 


\section{Introduction}

Logos are mainly vector graphics that form an integral part of the visual communication strategies developed for individuals, groups and businesses. Logos are the simplest form of brand identity usually represented by a mark or icon. Businesses are identified and differentiated by their visual identities. A logo is a single graphic design application that appears in all brand design applications (Landa, 2010). The competitiveness amongst businesses for public attention and patronage necessitates the need for a strong dynamic visual representation. Logos function as signifiers, denotative, point of contact and identifiers. Historically, logos emanated from the need to create recognizable patterns for identification. Animals were marked with unique symbols so that the owner could lay claims to them when the need arises. The practice involved heating a branding iron that was fashioned into a symbol, letter or name, in a fire, which would then be pressed against the hide of an animal, burning the hair and skin and leaving a permanent scar on the body (Regan, 2007). Also, the social revolution led to the establishment of forgery, counterfeiting, and fraud laws in 1905 for civil protection against the use of logo trademarks without authorization within the United Kingdom (West, 1978).

Logos communicate a sense of assurance and project organizations positively to the public. Logo positioning improves brand recognition and leverages all-inclusive brand equity. The consistent utilization of logos across the brand's communicative channels for a good period elicits a high recall of the brand by the public. Brand value is gained when visual identity arouses public memories and communicates a perception of excellence. Therefore, a logo is a sign of promise and fulfilment to the audience. It represents and embodies the entirety of a brand, group, or individual it signifies. Logos are often used exclusively in outdoor advertisements due to space and time constraints. Logos can be a wordmark that is wholly typographic constituting the nomenclature of the brand; or, symbolic. Symbolic logos combine pictorials with typography depending on the concept. The different categories of symbolic logos are highlighted as follows:

i. Letterform: These logos are developed using the initials of the company

ii. Symbol: symbolic logos are either pictorial or abstract.

iii. Non-objective Logos: These logos are outrightly invented and not visually influenced persons, places or object

iv. Character icon: A character icon showcases the personality of a brand, cause, or group 
v. Emblem: a combination of words and images that are always seen together, never separated (Landa, 2010).

The components of the logo refer to the graphic elements that constitute the content of logos and the style of presentation. Graphic contents are defined by colours and the idea being conveyed by the concept. Integration of colours in the logo creates visual balance. The colour composition can be monochrome, two, three or four colours. Aslam, emphasizes the importance of colour in corporate and marketing communication as follows:

Color is the medium of communication and is an integral element of corporate communications, it induces emotion and moods, impacts on consumers' perceptions, behavior and differentiates organizations from competitors. (Aslam, 2006)

However, the core values of individuals, businesses or groups drive the development of an effective logo. The design processes are guided by insight and intuition, information gathered and interpreted to align with the core values of the group or business. Aesthetic value and visual quality are essential in stimulating and enabling high recognition of the logo. Also, simplicity of style in logo design facilitates seamless and faster mental processing of the logo contents. According to Clark's study, people remember simple figures more easily than complex ones (Lawless, 1978). Geometric shapes are often utilized as the building blocks of logos. Shapes are the expression of the concept rationale imbued in the brand image. These shapes have suggestive meanings that correspond with the spelledout core values of brands. Adir, Adir and Pascul (2012) highlight the suggestive visual meanings of selected shapes as shown in Table 1:

Table 1: Suggestive meaning of Shapes

\begin{tabular}{|l|l|}
\hline Geometric Shape & Suggestive Induction \\
\hline Circle & Perfection and Balance \\
\hline Square & Stability and Power \\
\hline Rectangle & Duration, Progress \\
\hline Ellipse & Continue searching \\
\hline Triangle & harmony, urge towards \\
\hline Spiral & advancement, detaching \\
\hline Sphere & perfection, finality \\
\hline
\end{tabular}

Source: (Adir, Adir and Pascul, 2012) 
This study reviewed the previous survey studies relating to logo use and consumer perception of logos and a hypothesis was generated. The research methodology adopted is quantitative, and the data collected from the field was analyzed using descriptive statistics. The results were discussed. Hence, conclusion recommendations and areas of further research were highlighted.

\section{Literature Review}

The rising need for identity design by individuals, groups and companies has attracted the interest of scholars and researchers in exploring the consumer's perception of logos. Researches focused on understanding the appropriateness of logo contents. Prior studies have shown that the presentation of the graphical contents influences consumers' perception of the brand. Janiszewski and Meyvis (2001), investigated the effects of the brand logo on processing fluency and judgment. Janiszewski and Meyvis (2001) posited that expressive stimulus in logos expectedly improves conceptual fluency existing and creating a meaning-based representation of stimulus to facilitate easy encoding. Luffarellin, Stamatogiannakis and Yang (2018) explored the visual asymmetry effect of logo design and brand personality on brand equity, the researchers posited that asymmetric logos improve consumers' evaluations of brands with stimulating personality and positively influence the market's financial valuation of the brands. The descriptiveness of logos has been emphasized by many researchers studying the pictorial contents of logos. Mahmood, Luffarellin, Mukesh, (2019) noted that descriptive logos positively influence brand evaluations, purchase intentions, and brand performance. Bayunitri and Putri (2016) espoused those pictorial contents of logos indicative of brands business are more effective. Mahajan (2014) revealed that the complex descriptiveness of logo pictorials makes it appealing to customers. Pimentel (1996), showed colored pictorials in geometric patterns to respondents who were asked to evaluate the content and visual quality. The outcome showed that the respondents placed stronger emphasis on content. From the foregoing discussions on literature review, inference and research structure, this study developed a null hypothesis stating that descriptive logos are more appropriate than simple nondescriptive brand logos. Based on the position of previous researches in this area, Apparently, the results of previous researches enunciated in this study revealed that descriptive and expressive brand logos are more favoured by the public. These researches were mostly done by marketing professionals with minimal inputs from graphic designers. Evidence has shown that expressive logos are often not scalable, flexible, and timeless (Cass, 2017: Haviv, 2019). Landa (2010) posited that the characteristics of a good logo are memorability, versatility, timelessness, coherence, simplicity, and flexibility. 


\section{Criterial for Visual Appropriateness of Logos}

The criteria for measuring the visual appropriateness of the logo are anchored on five characteristics. These characteristics are significant in the conceptualization and development of brand logos that are considered to be efficient and effective in communicating brand personalities and potentials. Haviv (2019), asserted that a good logo communicates a feeling of appropriateness which is a function of simplicity, memorability, distinctiveness, and versatility. These four criteria are discussed as follows:

\section{a. Simplicity}

The simplicity of logos makes it easily recognizable and versatile. Simple logos instantly catches the attention of the intended audience at a glance. According to the Portuguese lexical online dictionary ${ }^{i}$, simplicity is a feminine substantive that may signify three qualities; quality of what is easy to understand or do, luxury absence: to live with simplicity; natural, spontaneity: to speak with simplicity. Simplicity enhances brand visibility and clarity amongst competing brands. Ray (2019) noted that simple logo design clearly communicates to the potential customers and nudge them towards embracing the brand

\section{b. Memorability}

Memorable logos oscillate between the thin line of familiarity and uniqueness, the image is simple to be easily recalled and unusually persist in the minds of the viewers (Stewart Design, 2020). Branded in Memory (2020) revealed that most participants struggled to recall exactly via their drawings the logos of globally renowned brands such as Apple, Addidas, and Domino Pizza. Memorable logos have simple and unique visuals which strategically convey the brands' message.

\section{c. Distinctiveness}

Distinctive features in logo design imply strong visual content, that is differentiable and edgy. Distinct cannot be confused with other brand trademarks-; visual concepts of distinct logos are original and identifiable. The quality of visuals in distinctive logos is engaging and bold.

\section{d. Versatility}

Versatile logos are scalable and easily reproducible on all communicative platforms. The scalability of logos implies that the visual element maintains proportion when resized. Logos are reproduced on different media platforms being the seal of brand communication. Versatile logos are designed to be reversible on light or dark backgrounds. 


\section{Methodology}

The research design for this study is quantitative. Thirty logo identities of businesses in the Telecommunication, Information Technology, Food/Beverage and Fashion were purposively selected based on the notability of the brands in the Nigerian market. The selected logos were subjected to the analysis of eighty respondents (80) constituting of thirty (30) formally trained graphic designers and ten (10) practicing printers based in Somolu and Mushin area of Lagos Metropolis and forty 40 consumers resident in Lagos that are familiar with the selected brands were also sampled. Lagos is the economic capital of Nigeria and is reputed for being the advertising and printing hub in Nigeria. Selected logos were further categorized into renowned brands and small-scale brands based on their market reach within and outside Nigeria. The determination of the appropriateness of the selected logos was measured using the criteria of appropriateness as articulated by Haviv (2019). These criteria are simplicity, memorability, distinctness, and versatility. Therefore, the average mean of the criteria indicates the appropriateness of the logos.

The statistical analysis of this study utilized five (5) point Likert scale formats Strongly Agree, Agree, Undecided, Disagree, and Strongly Disagree to collect data from the study population. The data collected were analyzed using the mean. The nominal scores and records were attained using the Likert scale model: Strongly Agree =5, Agree=4, Undecided $=3$, Disagree $=2$, and, Strongly Disagree $=1$. These were calculated as $5+4+3+2+1=15 / 5=3$ (Likert Scale Criterion). The score of each item was summed and the arithmetic means calculated for each item. The mean is compared with the Likert Scale criterion above (Angyol, 2015). If the mean is equal to or above (greater than) the Likert criterion (3.0) then the item is accepted and if the mean is lower than the Likert Scale criterion of (3.0) then the item is rejected. The mean scores and standard deviation values were calculated using the Statistical Package of Social Science (SPSS). Therefore, the average mean score of (3.0) indicates the appropriateness of each of the logos.

One null hypothesis was formulated and tested in the study. The hypothesis was tested using the pair sampled $t$-test to test the significant difference between two independent variables. All hypotheses formulated were tested using $\alpha(0.05)$ level of significance. 


\section{Results}

The results of the survey are presented in Tables $2,3,4,5,6,7.8$ and 9.

Table 2: Mean Values of Brand Logos (1)

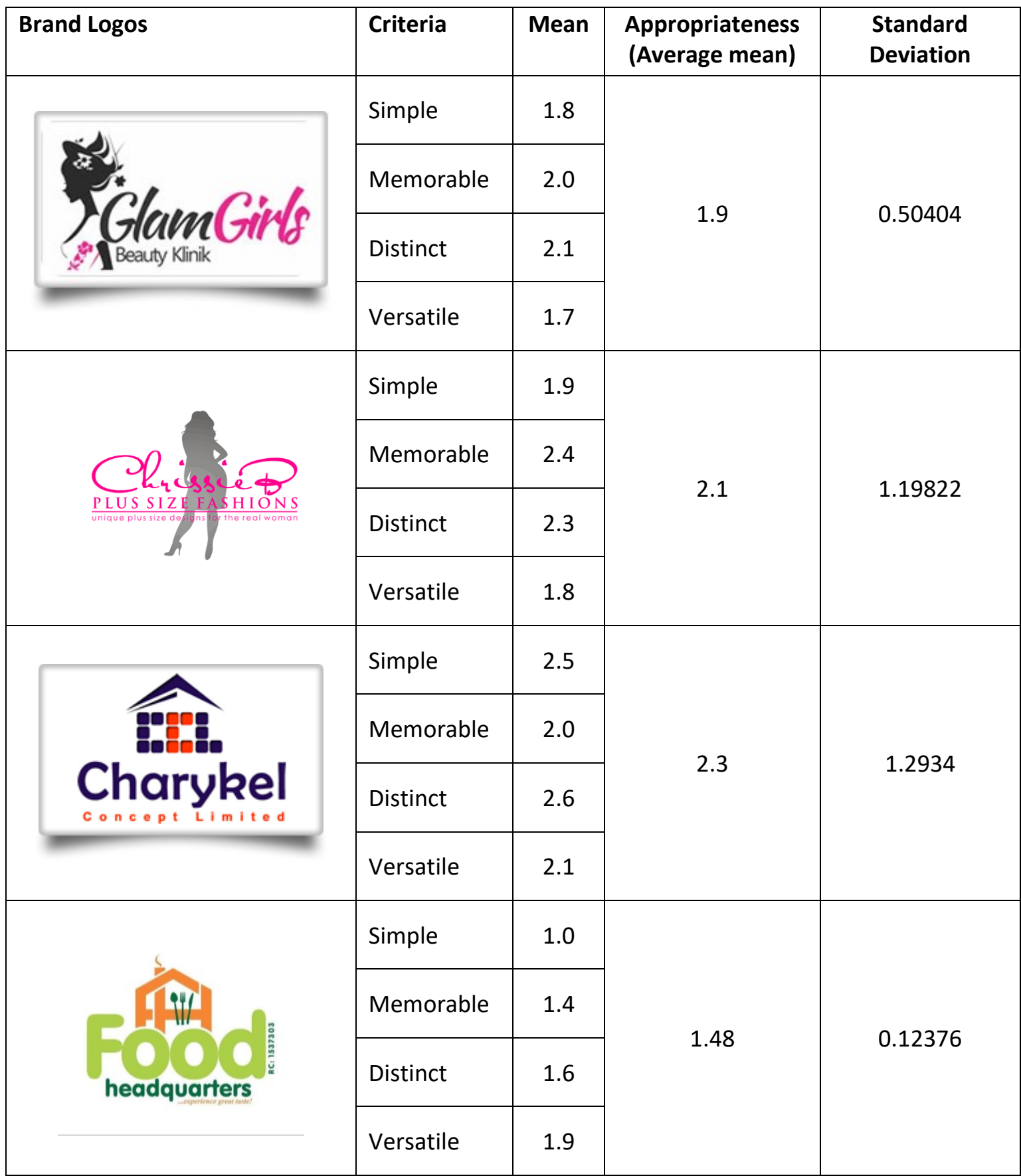

Source (Researchers' fieldwork, 2020). See also copyright note. 
Table 3: Mean Values of Brand Logos (2)

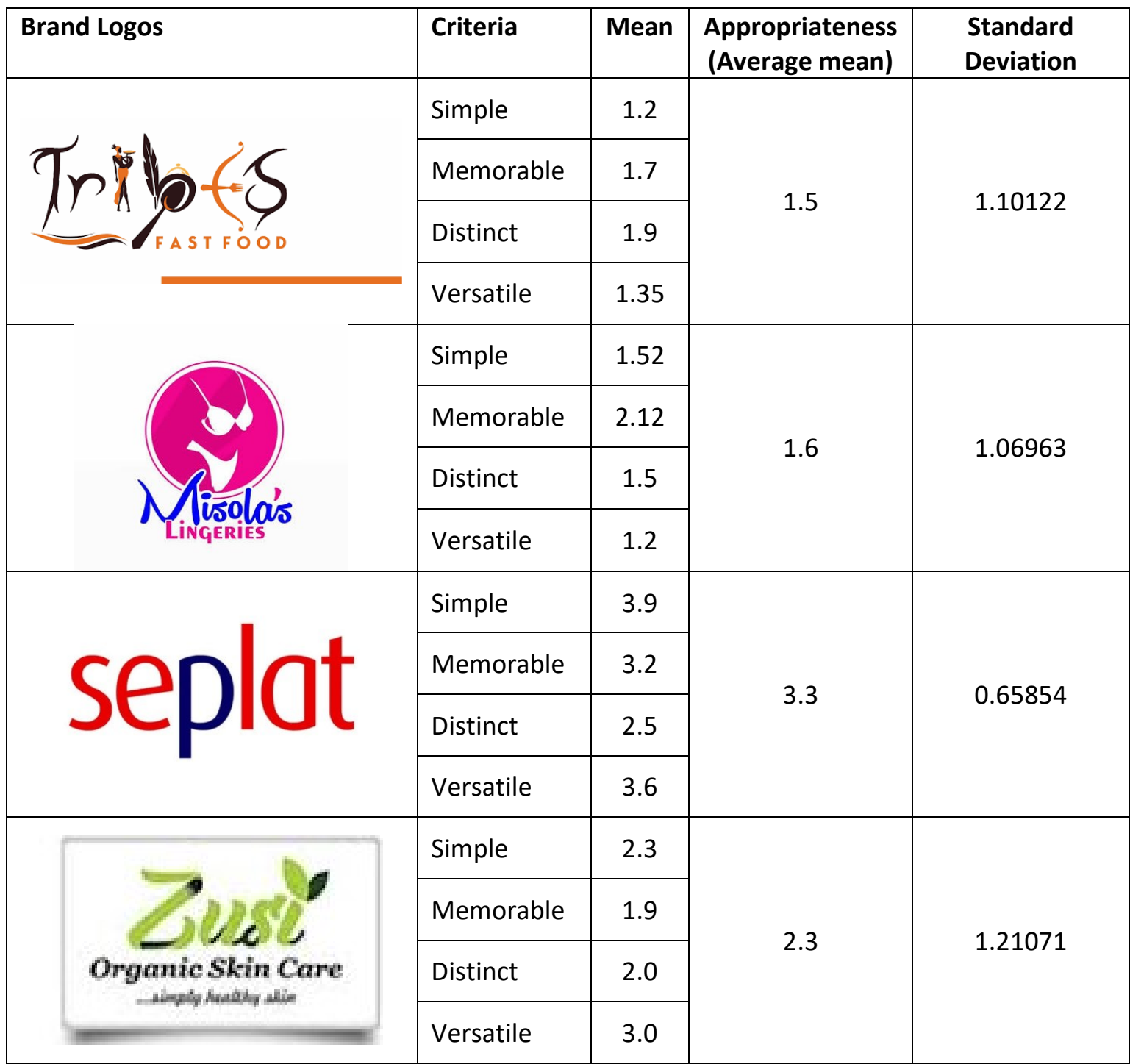

Source (Researchers' fieldwork, 2020). See also copyright note. 
Table 4: Mean Values of Small-Scale Brand Logos

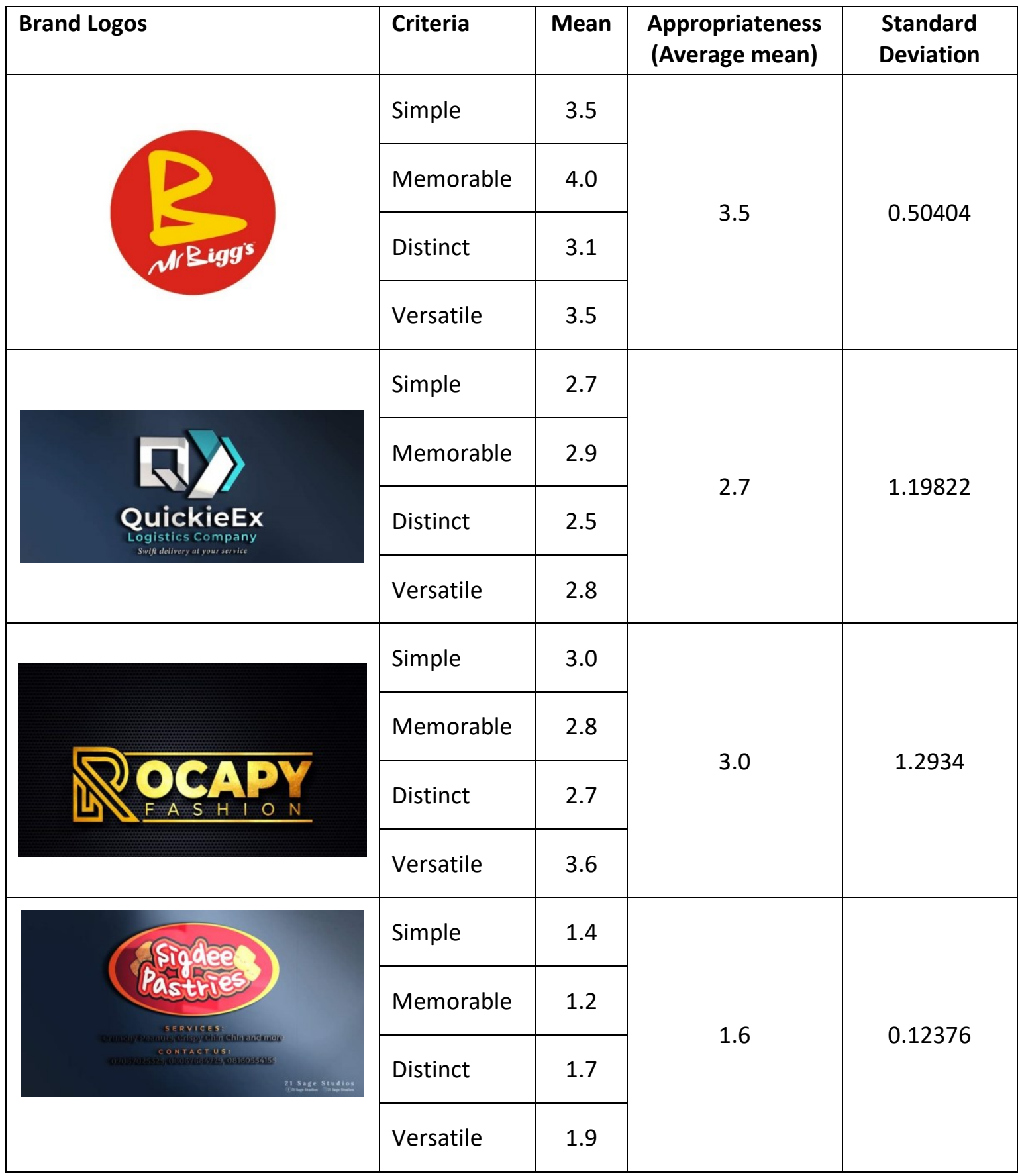

Source (Researchers' fieldwork, 2020). See also copyright note. 
Table 5: Mean Values of Brand Logos (3)

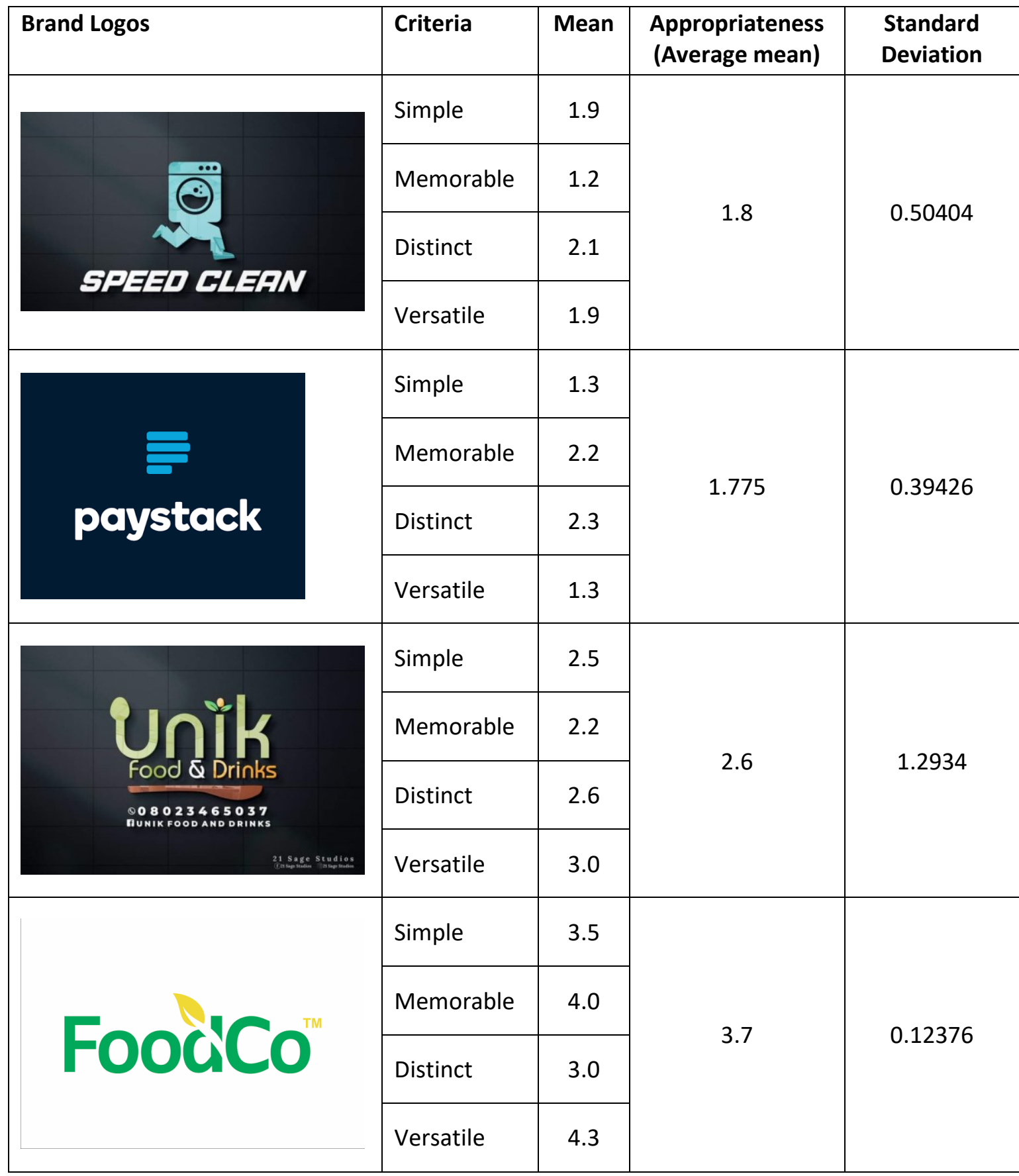

Source (Researchers' fieldwork, 2020). See also copyright note. 
Table 6: Mean Values of Brand Logos (4)

\begin{tabular}{|c|c|c|c|c|}
\hline Brand Logos & Criteria & Mean & $\begin{array}{l}\text { Appropriateness } \\
\text { (Average mean) }\end{array}$ & $\begin{array}{l}\text { Standard } \\
\text { Deviation }\end{array}$ \\
\hline & Simple & 1.3 & \multirow{4}{*}{1.55} & \multirow{4}{*}{1.01235} \\
\hline & Memorable & 2.1 & & \\
\hline & Distinct & 1.5 & & \\
\hline & Versatile & 1.3 & & \\
\hline \multirow{4}{*}{ kilimanjarê } & Simple & 3.5 & \multirow{4}{*}{3.3} & \multirow{4}{*}{0.48771} \\
\hline & Memorable & 2.7 & & \\
\hline & Distinct & 3.0 & & \\
\hline & Versatile & 3.9 & & \\
\hline \multirow{4}{*}{ 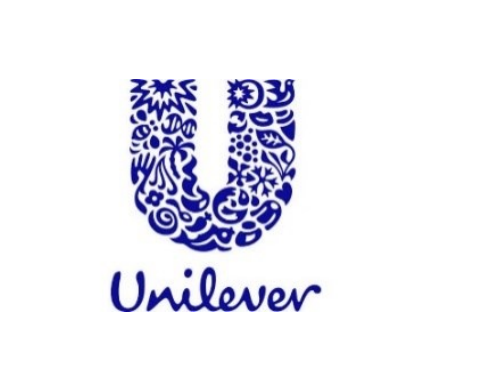 } & Simple & 3.0 & \multirow{4}{*}{3.5} & \multirow{4}{*}{0.85484} \\
\hline & Memorable & 3.1 & & \\
\hline & Distinct & 4.0 & & \\
\hline & Versatile & 3.7 & & \\
\hline \multirow{4}{*}{ B JULIUS BERGER } & Simple & 4.2 & \multirow{4}{*}{4.2} & \multirow{4}{*}{0.65824} \\
\hline & Memorable & 4.3 & & \\
\hline & Distinct & 4.1 & & \\
\hline & Versatile & 4.23 & & \\
\hline
\end{tabular}

Source (Researchers' fieldwork, 2020). See also copyright note. 
Table 7: Mean Values of Brand Logos (5)

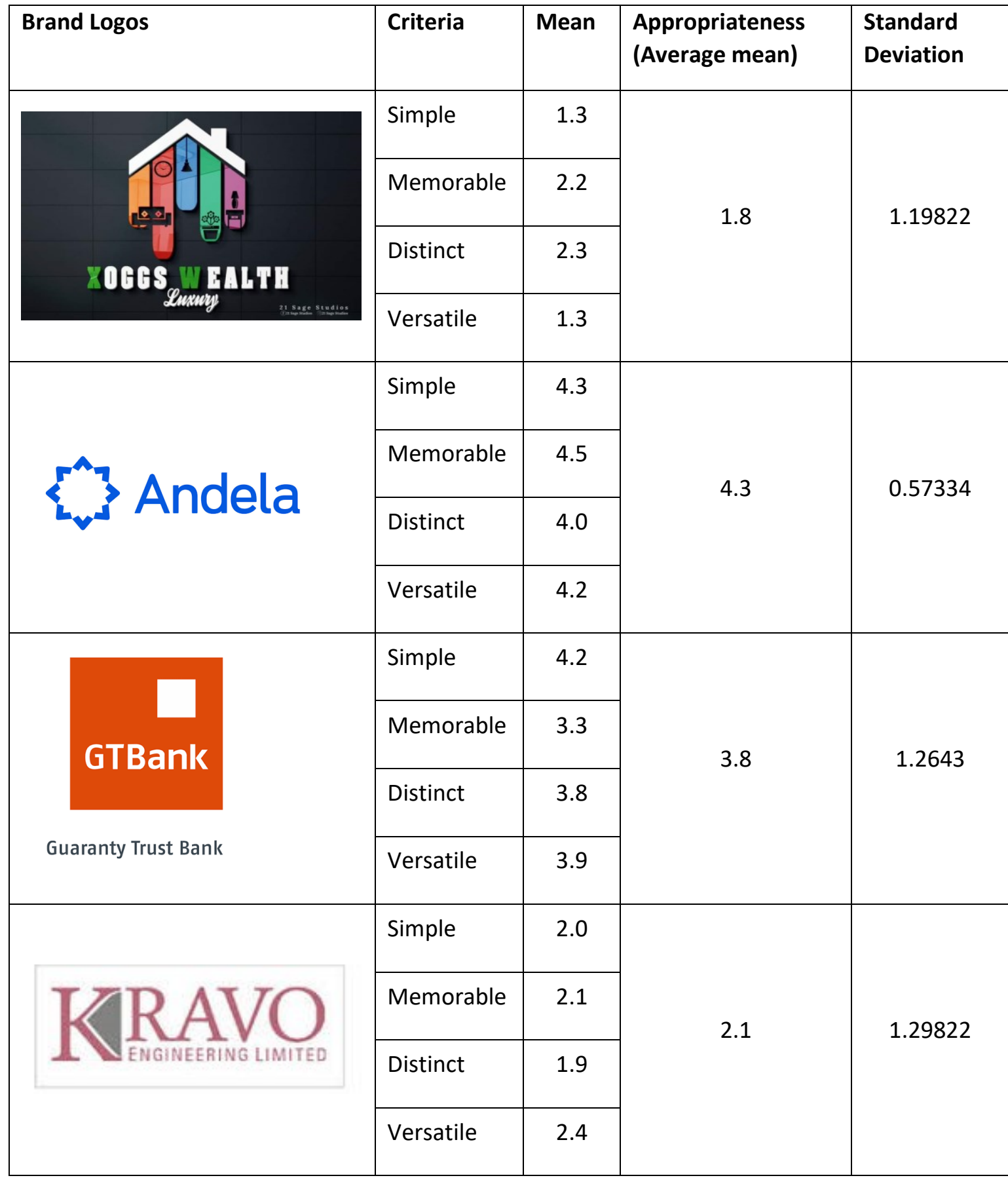

Source (Researchers' fieldwork, 2020). See also copyright note. 
Table 8: Mean Values of Brand Logos (6)

\begin{tabular}{|c|c|c|c|c|}
\hline Brand Logos & Criteria & Mean & $\begin{array}{l}\text { Appropriateness } \\
\text { (Average mean) }\end{array}$ & $\begin{array}{l}\text { Standard } \\
\text { Deviation }\end{array}$ \\
\hline \multirow{4}{*}{1} & Simple & 4.1 & \multirow{4}{*}{4.15} & \multirow{4}{*}{0.39426} \\
\hline & Memorable & 3.8 & & \\
\hline & Distinct & 4.3 & & \\
\hline & Versatile & 4.4 & & \\
\hline \multirow{12}{*}{2} & Simple & 4.4 & \multirow{4}{*}{4.2} & \multirow{4}{*}{0.57334} \\
\hline & Memorable & 3.6 & & \\
\hline & Distinct & 4.2 & & \\
\hline & Versatile & 4.4 & & \\
\hline & Simple & 4.0 & \multirow{4}{*}{3.7} & \multirow{4}{*}{1.2643} \\
\hline & Memorable & 3.2 & & \\
\hline & Distinct & 4.3 & & \\
\hline & Versatile & 3.3 & & \\
\hline & Simple & 4.3 & \multirow{4}{*}{4.1} & \multirow{4}{*}{0.65854} \\
\hline & Memorable & 4.1 & & \\
\hline & Distinct & 3.4 & & \\
\hline & Versatile & 4.4 & & \\
\hline
\end{tabular}

Source (Researchers' fieldwork, 2020). See also copyright note. 
Table 9: Mean Values of Renowned Brand Logos

\begin{tabular}{|c|c|c|c|c|}
\hline Brand Logos & Criteria & Mean & $\begin{array}{l}\text { Appropriateness } \\
\text { (Average mean) }\end{array}$ & $\begin{array}{l}\text { Standard } \\
\text { Deviation }\end{array}$ \\
\hline & Simple & 3.2 & \multirow{4}{*}{3.5} & \multirow{4}{*}{0.39426} \\
\hline & Memorable & 3.3 & & \\
\hline yy to inspire & Distinct & 4.1 & & \\
\hline & Versatile & 3.4 & & \\
\hline \multirow{4}{*}{ 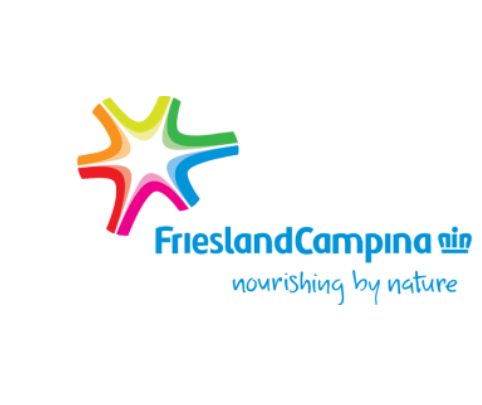 } & Simple & 4.1 & \multirow{4}{*}{3.8} & \multirow{4}{*}{0.57334} \\
\hline & Memorable & 3.5 & & \\
\hline & Distinct & 4.4 & & \\
\hline & Versatile & 3.3 & & \\
\hline \multirow{4}{*}{ Deloitte } & Simple & 4.5 & \multirow{4}{*}{4.025} & \multirow{4}{*}{1.2643} \\
\hline & Memorable & 4.3 & & \\
\hline & Distinct & 3.4 & & \\
\hline & Versatile & 3.9 & & \\
\hline \multirow{4}{*}{$\begin{array}{l}\text { sogs } \\
\text { Nestle }\end{array}$} & Simple & 3.4 & \multirow{4}{*}{3.6} & \multirow{4}{*}{0.65854} \\
\hline & Memorable & 3.2 & & \\
\hline & Distinct & 3.8 & & \\
\hline & Versatile & 3.9 & & \\
\hline
\end{tabular}

Source (Researchers' fieldwork, 2020). See also copyright note.

Simplicity

Some of the brand logos resonate with simplicity while others do not. However, it was observed that the logos of some small-scale brands look complex (see Figure 1). The common misconception about the logo is that it should be a medium of showcasing the form of business rather than being a simple business identifier. 
Figure 1: Simplicity in Logo

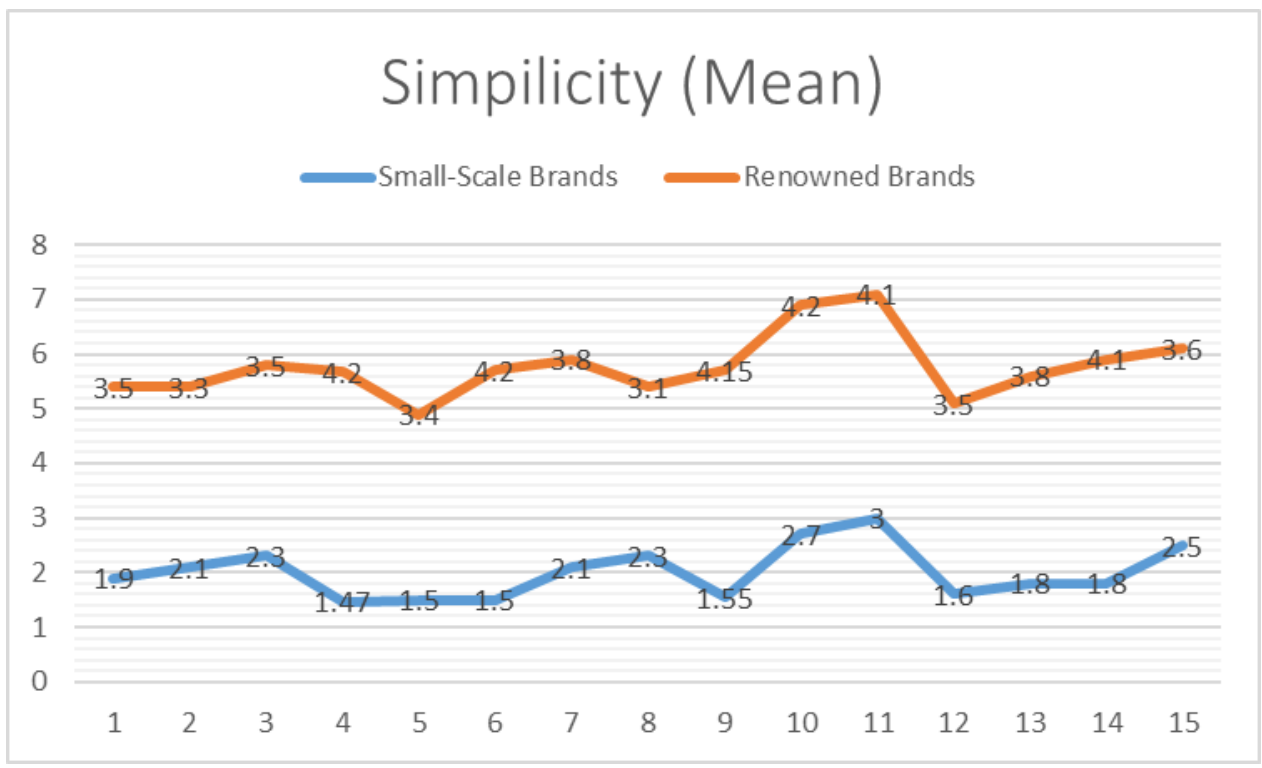

Source: (Researchers' Fieldwork, 2020)

\section{Memorability}

The Logos of sampled renowned brands are more memorable than the small-scale brands as shown (see Figure 2).

Figure 2: Memorability in Logo

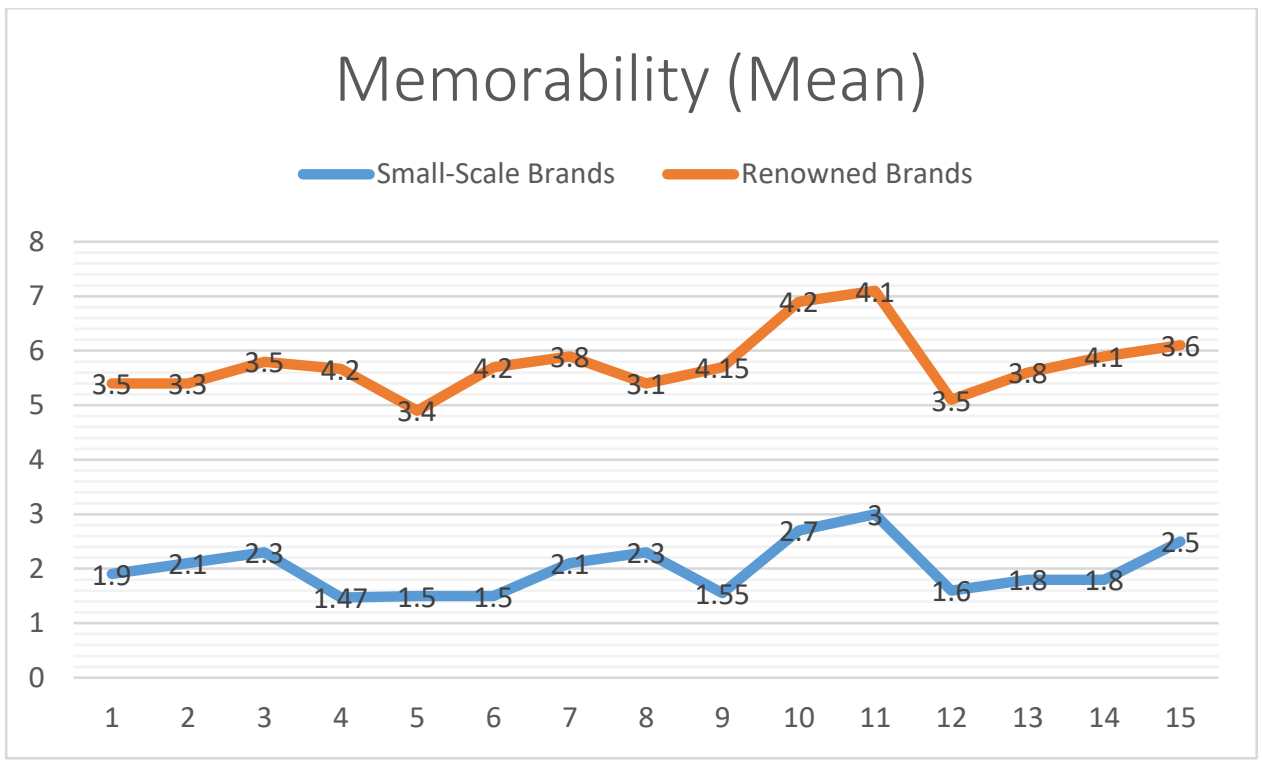

Source: (Researchers' Fieldwork, 2020)

\section{Distinct}

The quality of visuals in distinctive logos is engaging and bold. Figure 3 shows that most of the renowned brand logo are distinctive in comparison to small-scale brand logos. 
Figure 3: Distinctiveness in Logo

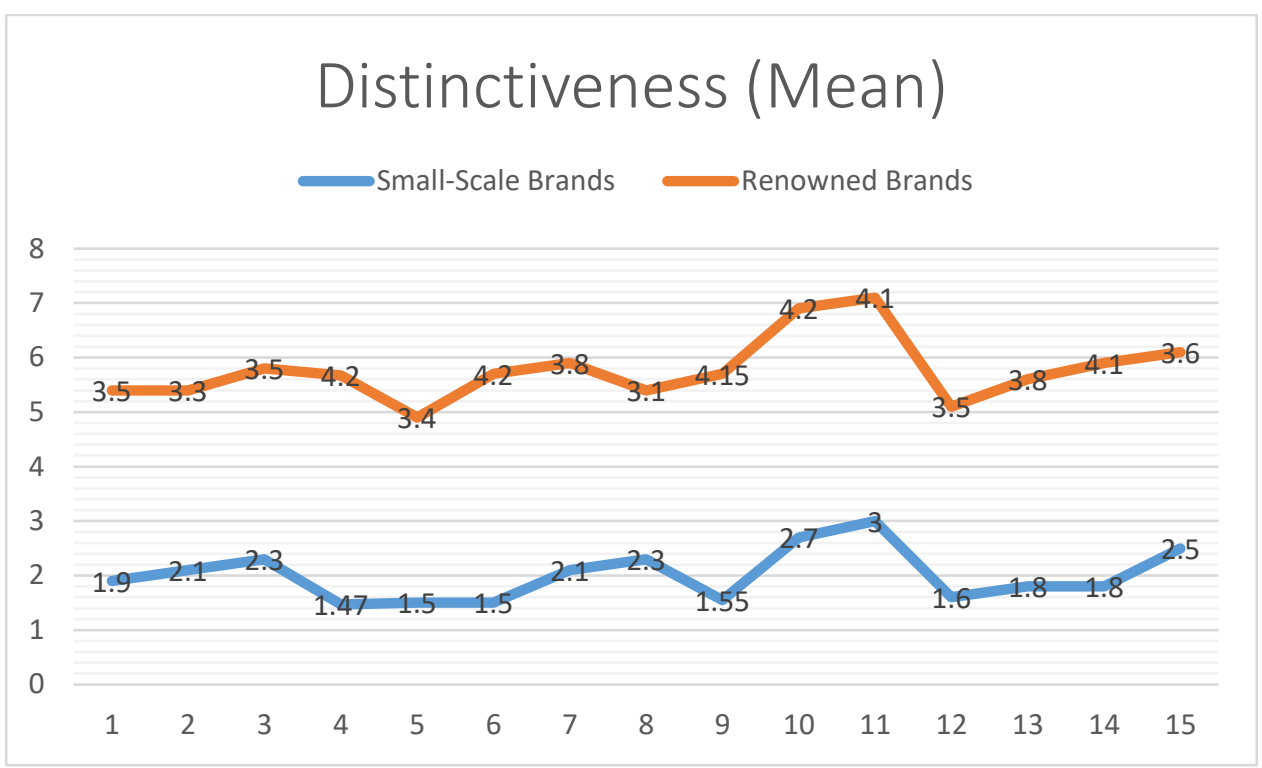

Source: (Researchers' Fieldwork, 2020)

Versatility

The versatility of logos is referred to the scalability and reproducibility properties of logos. Simple logos are scalable and reproducible. The renowned logos are mostly versatile as shown (see Figure 4).

Figure 4: Versatility of Logo

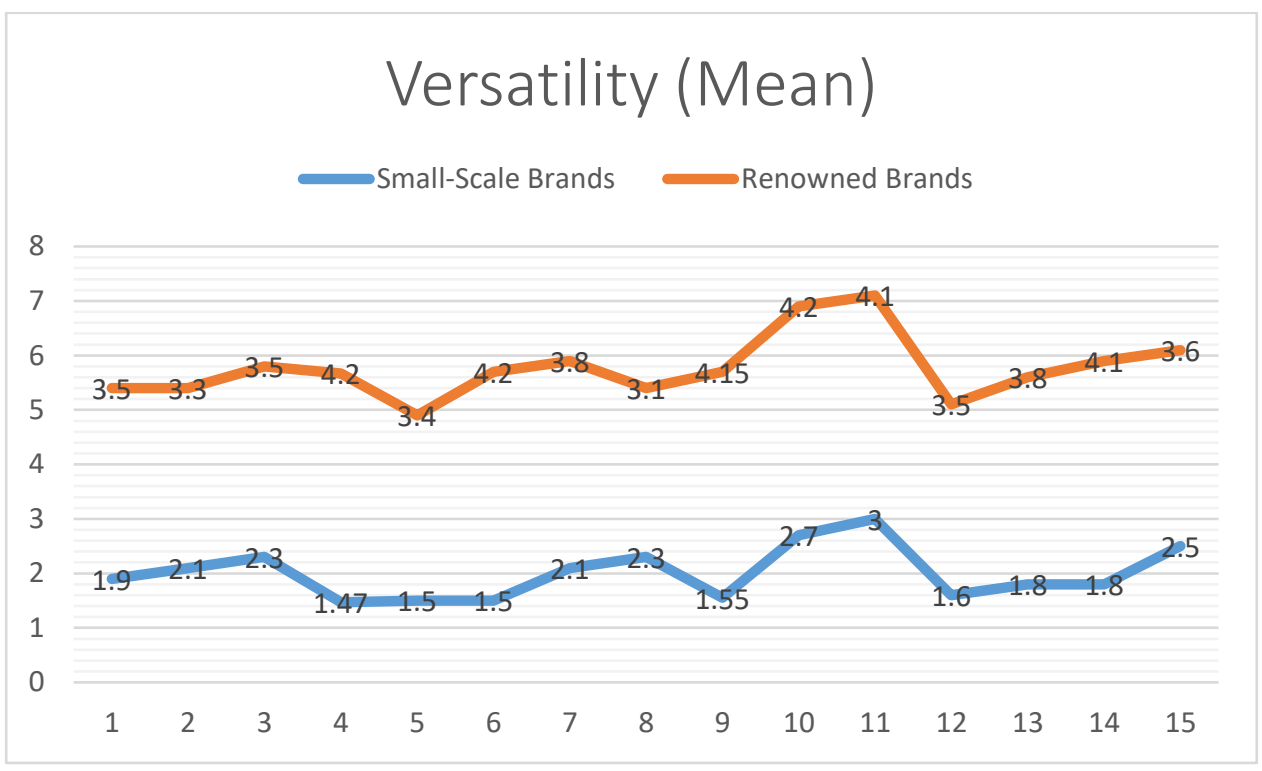

Source: (Researchers' Fieldwork, 2020) 


\section{Appropriateness}

The average mean value of (3.0) and above is an indication of the appropriateness of a logo while (2.9) and below represent a nonappropriateness of a particular logo. Figure 5 shows that just two logos amongst the small-scale brand logo can be classified as being appropriate. While the renowned brand logos are all appropriate.

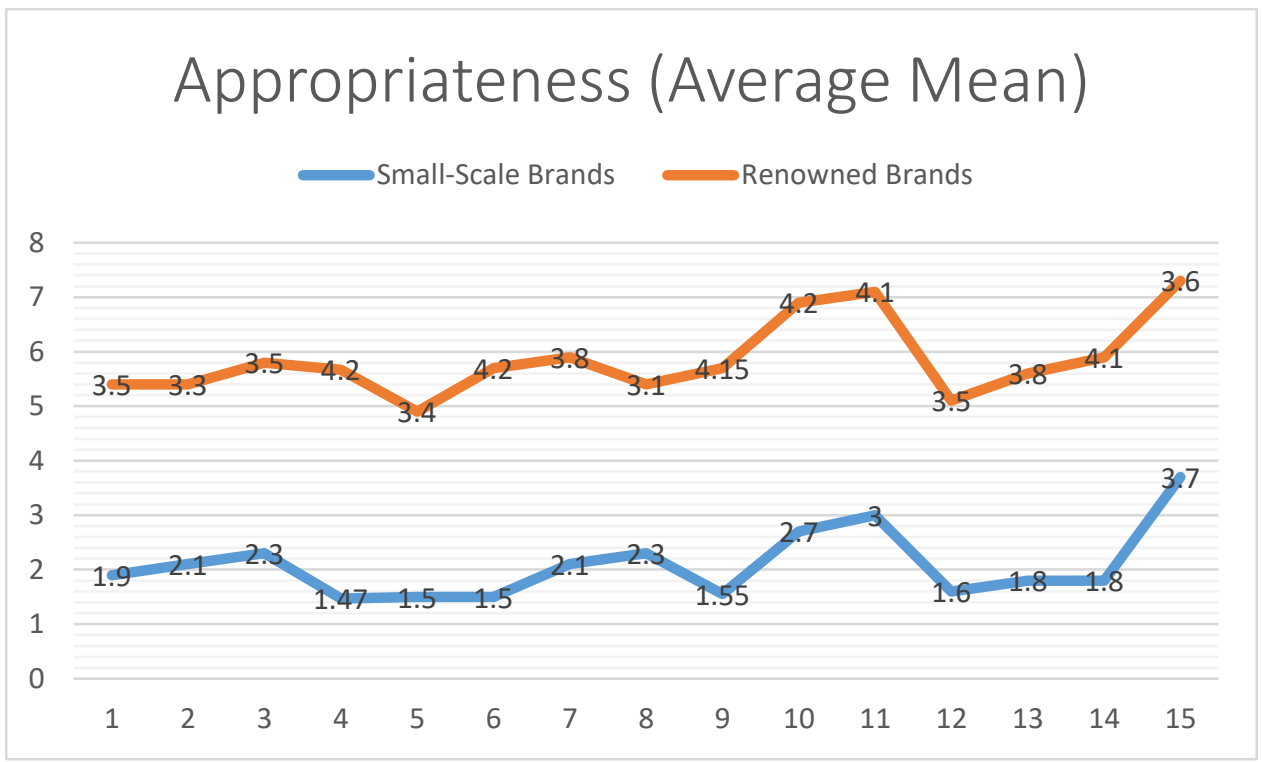

Source: (Researchers' Fieldwork, 2020)

\section{Testing of Null Hypotheses}

\section{Hypothesis One:}

Ho: Descriptive brand logos are more appropriate than Simple and nondescriptive brand logos

Table 10 shows that the mean and standard deviation of descriptive logos and non-descriptive/simple logos are 1.9 and 3.7 and 0.71 respectively. The $t_{\text {cal }}=6.16>t_{\text {crit }}=1.97$ and the $P_{\text {value }}=0.0001<0.05$. Simple brand logos are more appropriate than descriptive brand logos. Therefore, the null hypothesis is rejected.

Table 10: Summary of paired sample t-test for hypothesis one

\begin{tabular}{|l|l|l|l|l|l|l|l|l|}
\hline Variable & $\mathbf{N}$ & Mean & S.D. & DF & Tcal & Tcrit & Pvalue $_{\text {Remark }}$ \\
\hline Descriptive Logo & 40 & 1.9 & 0.93 & 311 & 6.16 & 1.97 & 0.0001 & Significance \\
$\begin{array}{l}\text { Simple/Non- } \\
\text { descriptive Logo }\end{array}$ & 40 & 3.7 & 0.71 & & & & \\
\hline
\end{tabular}

* Significant at $\mathrm{P} \leq 0.05$. Source: (Researchers' Fieldwork, 2020) 


\section{Discussions and Theoretical Contributions}

The average mean results of each of the evaluated criteria are discussed in relation to the visual appropriateness of the brand logos. The average mean values of 3.8 and 2.0 indicate the simplicity that characterizes the sampled brand logos. Simplicity is an essential feature of logos. Simple logos are easily processed by the public and communicate the vitality of brands. Complex logo designs possess multiple signals that lead to confusion in viewer's minds (Ray, 2019). The simplicity of logos enables easy recognition of logos and makes them endure for a long period of time. The sampled logos that are descriptive do not resonate with simplicity because the logos are complex and crammed with different design elements. An average mean value of 1.9 and 3.8 indicate the memorability of logos of the sampled brands. Simple logos are memorable; memorable logos are less crammed with colours and pictorial contents.

The average mean values of 4.0 and 1.8 show the distinctiveness of logos of the brands. Small-scale logos are not versatile because of their descriptive nature, they are complex and loses qualities when resized. This is evident in the average mean values of 3.8 and 2.0 revealing the versatility of the logos. This study measured appropriateness as the average of the mean values of the specified criteria, this position is informed by the assertion of Haviv (2019). The outcome of this study reflects the processes often adopted by brands in the creation of their logos. Observably, expressive and complex logos are not versatile, reproducible, and memorable. Multinational brands engage established Advertising/Design firms who go through the thorough procedure of conducting brand strategy which is fundamental to logo development. The procedure is mostly devoid of personal sentimentalities of the business owners which enable the Design firms to create an appropriate logo for the client. However, some brand owners often want the visual content to express their nature of business. They misconstrue logos to be a medium of communication rather than identification and this misconception is reflected in the quality of logos developed for small-scale businesses.

\section{Implications for Practice}

This study provides a dynamic approach to the conceptualization and development of logos. It enunciates the fundamental features that constitute the perceived appropriateness of logos. Logos are very important to brands because that is the visual element that considerably influences consumer perception and acceptability of brands. Logos are visual seals that communicate brand promises to the targeted viewers. The professionals in the advertising field who are saddled with the responsibility of creating logos for businesses, individuals, or groups are 
expected to consider the factors highlighted below when developing a logo:

i. The visual contents of logos should resonate with good spacing and balance.

ii. Application colours in logos should be limited to two.

iii. Logos design should be a product of a sound brand strategy.

iv. The pictorial contents of logos should be less visually descriptive.

v. Expressive logos are less memorable and versatile.

vi. Logos should retain their uniqueness irrespective of colours or size.

\section{Conclusion}

Logos represent a significant aspect of brand strategies and campaigns. The perception of brand logos communicates a feeling of brand value to the public. Logos that are simple, distinct, memorable, and versatile are considered appropriate. Appropriate logos are timeless and suitable for a medium of brand communication without being distorted or reworked. Globally renowned brands are reputed for their enduring visual identities and timeless logo. Inappropriate logos are susceptible to change which hurts the emotional connection existing between the loyal customers and the brand. Logo designers need to ensure that the visual contents of logos are created in such a way that they are reversible on light and dark backgrounds. The expressiveness and depiction in the visual contents of logos create multiple signals and visual complexities that make the brands less valuable. Appropriate logos are sustainable visual flags that connect the public to the brand.

\section{Areas of Further Research}

Further research needs to focus on evaluating the psychological and cultural perception of colours used in logos. The psychological impact of colour is often indicative of the services offered by brands, it could also be reflective of the target demography of the audience. Apparently, the logo constitutes the visual liveries of brands. Also, the perception of colours is dependent on cultural implication which varies according to the tradition and custom of different societies. Hence, the choice of colours for the brand logo could also be determined by the culture of the target audience.

\section{Copyright Note}

All logos are included under fair-dealing for the purposes of research and analysis within the body of this work by the authors, and remain (C) their respective rights holders. 
Dr. Siyanbola Afeez Babatunde, is a lecturer in the Department of Fine and Applied Olabisi Onabanjo University. He has B.Tech and M.Tech in Industrial Design Department (Graphics Option) Federal University of Tecnology Akure. He also bagged his Doctoral Degree from Industrial Design Department of Ahmadu Bello University in Zaria. His Ph.D. research focused on e-commerce user experience. $\mathrm{Dr}$ Siyanbola is a brand consultant and photographer. He has presented in both local and international conferences.

\section{List of Tables}

Table 1: Suggestive meaning of Shapes .47

Table 2: Mean Values of Brand Logos (1) ................................................51

Table 3: Mean Values of Brand Logos (2) .............................................52

Table 4: Mean Values of Small-Scale Brand Logos....................................53

Table 5: Mean Values of Brand Logos (3) .............................................54

Table 6: Mean Values of Brand Logos (4) ...............................................55

Table 7: Mean Values of Brand Logos (5) ...............................................56

Table 8: Mean Values of Brand Logos (6) ..............................................57

Table 9: Mean Values of Renowned Brand Logos.....................................58

Table 10: Summary of paired sample t-test for hypothesis one ..............61

\section{List of Figures}

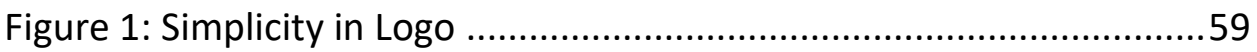

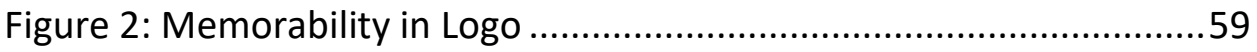

Figure 3: Distinctiveness in Logo .............................................................60

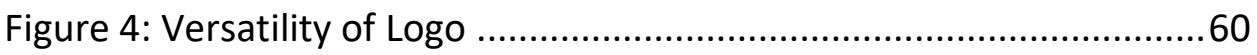

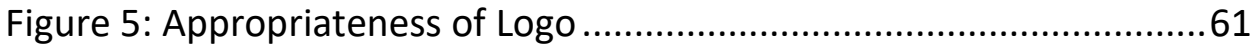

\section{References}

Adir, Adir and Pascul (2012). Logo design and the corporate identity. Procedia Social and Behavioral Sciences, 51:650-654.

Angyol, M. A. (2015). Development of Alphabet Multimedia Instructional Materials to Enhance Pre-Primary Pupils Education in Samaru Zaria, Kaduna State Nigeria. An Unpublished Masters Dissertation Department of Industrial Design, Ahmadu Bello University Zaria.

Aslam M. (2006). Are You Selling the right Colour? A cross-cultural review of colour as a marketing cue. Journal of Marketing Communication, 12(1): 15-30. 
Bayunitri B and Putri S. (2016). The Effectiveness of Visualization the Logo Towards Brand Awareness. Procedia-Social and Behavioural Sciences, 219: 134139.

Branded in Memory (2020). 10 Iconic Logos. 156 Americans. 80 hours of drawing from memory. Available at: https://signs.com/branded-in-memory [Accessed: 5 September 2020].

Cass J. (2017). Logo Simplicity. Available at: https://justcreative.com [Accessed: 24 September 2020].

Haviv W (2019). What makes a Logo Great and Iconic. An online interview. Available at: https://thefutur.com [Accessed: 14 July 2020].

Janiszewski C and Meyvis T (2001). Effects of Brand Logo Complexity, Repetition, and Spacing on Processing Fluency and Judgement. Journal of Consumer Research, 28(1): 18-32. DOI: 10.1086/321945 [Accessed: 14 July 2020].

Landa, R. (2010). Graphic Design Solutions. Wadsworth Cengage Learning, Boston, USA.

Lawless H. (1978). Recognition of common odors, pictures, and simple shapes. Perception \& Psychophysics, 1978, 24(6): 493.495.

Luffarellin J. Stamatogiannakis A. and Yang H. (2018) The Visual Asymmetry Effect: An Interplay of logo design and Brand Personality on Brand Equity. Journal of Marketing Research, 56(1): 89-103. DOI: 10.1177/0022243718820548 [Accessed: 14 July 2020].

Luffarelli J. Mukesh M. and Mahmood A. (2019). Let the Logo do the Talking: The Influence of Logo Descriptiveness on Brand Equity. Journal of Marketing Research, 56(5): 862-878. DOI: 10.1177/0022243719845000 [Accessed: 14 July 2020].

Mahajan N. (2014). An Exploration of Imapact of Logo Redesign and Brand Image. Global Journal of Finance and Management. 6(3): 209-216.

Pimentel, R W. (1996). I don't know much about design, but I know what I like: An exploratory study of preference for visual images. Working paper, University of Central Florida.

Ray H. (2019). Simplicity, A Huge Contributing factor to Logo Design. Available at: https://designhill.com [Accessed: 7 September 2020].

Regan, A. (2011): A brief history of branding. Available at: http://www.articlesbase.com/branding-articles/a-brief-history-of-branding252518.html [Accessed: 12 June 2018].

Stewart Design (2020). Principle of Effective Logo Design: Memorable (Part II). Available at: https://sdidentity.com [Accessed: 2 September 2020]. 
Walsh, F, Page K, and Mittal V. (2006). Logo Redesign and Brand Attitude: The Effect of Brand Commitment. ACR 2006 Conference, September Orlando, Florida.

West, E. G. (1978) Literacy and the Industrial Revolution. Economic History Review, 31(3): 369-383.

\section{To cite this article:}

Siyanbola, A., \& Adeyemi, A., 2021. An Assessment of the Visual Appropriateness of Selected Brand Logos. Exchanges: The Interdisciplinary Research Journal, 9(1), 45-66. Available at: https://doi.org/10.31273/eirj.v9i1.800.

\section{Endnotes}

i See: http://www.lexi-co.pt/simplicidade/ 